\title{
DECISÃO ESTRATÉGICA EM UMA INSTITUIÇÃO DE ENSINO SUPERIOR PÚBLICA A PARTIR DA FERRAMENTA ANÁLISE DO CUSTO-ALUNO
}

\section{ARTIGO ORIGINAL}

DANTAS, Luiz Antonio de Oliveira ${ }^{1}$

DANTAS, Luiz Antonio de Oliveira. Decisão estratégica em uma Instituição de Ensino Superior Pública a partir da Ferramenta Análise do Custo-Aluno. Revista Científica Multidisciplinar Núcleo do Conhecimento. Ano 04, Ed. 12, Vol. 07, pp. 71 92. Dezembro de 2019. ISSN: 2448-0959, Link de acesso: https://www.nucleodoconhecimento.com.br/contabilidade/decisaoestrategica

\section{RESUMO}

Decisões estratégicas em empresas são fundamentais para a perenidade das instituições. O papel da contabilidade gerencial e financeira, nesse sentido, é de contribuir para a racionalidade do ponto de vista econômico-financeiro. Apesar das sucessivas crises no modelo educacional no Brasil, é notável o crescimento da competição no setor, da educação básica à pós-graduação, em empresas públicas ou privadas. Mais a mais se discute sobre o papel do estado na educação, nas suas diferentes dimensões, especialmente diante das restrições orçamentárias do país e em razão das demandas do ponto de vista legal. Assim, esse estudo teve por objetivo refletir sobre a sustentabilidade financeira de uma IES pública. A contribuição se faz a partir do custo-aluno em uma instituição de ensino superior do setor público brasileiro com o propósito de otimizar os processos de tomada de decisão gerencial, elaborando, para isso, um protótipo de sistema de custos baseado no modelo de custeio espanhol de Díaz et al (2013), modelo este que foi desenvolvido especificamente para universidades. Realizou-se uma pesquisa-ação de abordagem

\footnotetext{
${ }^{1}$ Mestrado em controladoria empresarial.
} 
construtivista por meio de uma proposta intervencionista, o que caracterizou a metodologia da pesquisa como exploratória, descritiva e intervencionista, e, dessa forma, contou com um processo de coleta de dados bibliográfico e documental por meio de entrevistas e observações em campo. Os resultados alcançados demonstraram o real custo por aluno da instituição da amostra, tanto no âmbito da graduação como da pós-graduação. Como principal contribuição técnica e acadêmica para a área, a partir da proposta intervencionista dessa pesquisa, gerou-se um protótipo de modelo de sistema de custeio baseado no modelo de custeio espanhol supracitado a partir do acesso a informações sobre custos e resultados relevantes.

Palavras-chave: Contabilidade Pública, custo-aluno, sistema de Custos, contabilidade de custos no Setor Público Educacional, decisão Estratégica - Financeira.

\section{INTRODUÇÃO}

A contabilidade de custos possui duas relevantes funções, segundo Martins (2010, p. 21), que são "o auxílio ao controle e a ajuda às tomadas de decisões". Sendo assim, identificar os custos e utilizar estas informações para a tomada de decisões propicia maior proficiência neste processo. Ao final, a principal contribuição do sistema de custos é viabilizar a busca pela economicidade, eficiência, eficácia e efetividade, sendo um importante instrumento de controle estratégico-financeiro. Marion (2015) afirma que a contabilidade de custos, ao nortear e estudar 0 desempenho organizacional, revela-se como um importante instrumento auxiliador a gestores de empresas e instituições ao mensurar potenciais efeitos econômicos das decisões gerenciais. Em Instituições Ensino Superior (IES), como em qualquer organização, a gestão de custos tem significativa relevância no processo de tomada de decisão gerencial.

É preciso destacar que o conhecimento efetivo do custo-aluno pode propiciar maior qualidade no serviço prestado bem como maior transparência e gestão eficiente. Sobre isso, Machado (2002), Siqueira (2006) e Faria (2010) convergem na ponderação de que serviços públicos de qualidade assim como transparência e eficiência quanto ao uso de recursos públicos são práticas desejadas pela sociedade. 
Estas práticas, para serem alcançadas e demonstradas, demandam, dos agentes públicos, ferramentas de gestão de custos implantadas a partir de modelos específicos de sistemas de custeio e de controle. O modelo, então, pode servir da mesma forma em uma IES pública, assegurando a utilização maximizada dos recursos cada vez mais escassos. Soares e Cericato (2005) apontam para a complexidade em identificar e comparar o custo-aluno em Instituições de Ensino Superior (IES).

Esta complexidade é devida à aplicação de metodologias de custeio diferentes que dificultam o cálculo do custo por aluno assim como a precificação de mensalidades e o processo de tomada de decisões gerenciais. Esta complexidade geral é agravada, ainda, em IES públicas, assentadas sobre práticas contábeis gerenciais e de controle específicas ao setor, necessárias, portanto, ao casamento entre efetividade gerencial na utilização dos recursos, na realização dos objetivos, na transparência, na conformidade e na aplicação do erário. A Legislação Brasileira dispõe sobre normas e regulamentações quanto às diretrizes da contabilidade de custos, gestão orçamentária e adoção de sistema de custos para o setor público. A temática tem sido pensada desde a legislação mais antiga, como a lei que dispõe sobre as normas gerais do direito financeiro para elaboração e controle dos orçamentos públicos (Lei n. $4.320,1964)$, passando pela Constituição Federal, em seu artigo 74, que trata da obrigatoriedade dos três poderes manterem o sistema de controle interno de forma integrada (Constituição do Brasil, 1988), até as leis, normas e instruções normativas mais recentes.

Diante disso, justifica-se a relevância desta pesquisa, pois o estudo tem como base as normas e instruções normativas brasileiras que regem e dispõem, em seus artigos, sobre as necessidades e obrigações voltadas à esfera da administração pública bem como sobre a devida prestação de contas, em consonância, paralelamente, à Lei Complementar 101/2000 - Lei de Responsabilidade Fiscal (LRF) que dispõe sobre normas relativas ao controle de custos e avaliação de resultados dos programas financiados com recursos dos orçamentos (Lei n. 101, 2000) e, ainda, o Acórdão n. 1078/2004 do Tribunal de Contas da União (TCU) que determina que a administração 
pública federal deve dispor de sistemas de custos que permitam a avaliação e acompanhamento da gestão orçamentária e financeira (Tribunal de Contas da União, 2004).

As Normas Internacionais de Contabilidade Aplicadas ao Setor Público, do inglês, International Public Sector Accounting Standards (IPSAS), de acordo com Chan (2009), remetem à versão governamental das Normas Internacionais de Contabilidade Aplicadas ao Setor Privado - International Financial Reporting Standards (IFRS) - e tornaram-se referências internacionais para a avaliação de práticas contábeis de governos em todo o mundo. Grande parte das IPSAS, portanto, pode ser definida como alterações modestas dos padrões promulgados pelo Internacional Accounting Standards Board (IASB), segundo o mesmo autor. No contexto brasileiro, Queiroz e Rodrigues (2012), mencionam que a convergência da contabilidade pública brasileira às IPSAS provocou alterações significativas, tanto conceituais quanto práticas, especialmente na estrutura das demonstrações contábeis.

Já as Normas Brasileiras de Contabilidade Aplicadas ao Setor Público (NBC TSP) que convergem com as IPSAS, têm como principal foco, de acordo com Machado, Freytag e Maliski (2012), o resgate da contabilidade patrimonial de forma a registrar e controlar, também, o patrimônio público e não somente o orçamento. Essa convergência das normas brasileiras com os padrões internacionais, de acordo com Gama, Duque e Almeida (2014), promete mudar a cultura organizacional dos gestores públicos que possuem visão puramente orçamentária e não patrimonial, sobretudo quando o assunto é a tomada de decisão. Diante do exposto, foi realizado um estudo para investigar as especificidades do custeio do serviço prestado a partir da análise de uma IES pública (autarquia municipal na Grande São Paulo) para, assim, responder a seguinte questão: quais fatores devem ser considerados e combinados para apuração do custo-aluno em uma IES pública?

A investigação dessas especificidades de custeio possibilitará não só a apuração propriamente do custo-aluno praticado na instituição estudada - objetivo específico como será capaz, principalmente, de subsidiar práticas de controle estratégicofinanceiros visando otimizar os processos de tomada de decisão gerencial que se 
relacionam, diretamente, com o desempenho financeiro da instituição, à luz do modelo da contabilidade analítica para universidades. Para o desenvolvimento deste estudo foi utilizada uma metodologia de custeio de serviços desenvolvida especialmente para instituições governamentais: trata-se do Modelo de Custeio Espanhol (MCE). O MCE foi desenvolvido especificamente para universidades pela Oficina de Cooperación Universitária (OCU) em parceria com a Universidade de Málaga (UMA), resultando em uma plataforma tecnológica sólida, e, também, dotada de conhecimentos funcionais.

O MCE foi publicado, pela primeira vez, em 2011, na obra de Díaz et al intitulada de "Libro Blanco de los Costes en las Universidades", com versão em língua portuguesa lançada no ano de 2013. O modelo utiliza como base (o método de custeio ABC Custeio Baseado em Atividades) propõe conectar e integrar todas as universidades que implantam o sistema que, por sua vez, remete à uma aplicação multilíngue, cujo funcionamento se dá inteiramente on-line (DIAZ et al, 2013). Martins e Peixinho (2017), em seu estudo sobre o desenvolvimento de um sistema de custos, analisando o caso da Universidade de Algarve, apontam diversos autores e estudos que convergem na afirmação do fato que um grau reduzido de universidades europeias implementam o método $\mathrm{ABC}$, embora um número maior dessas universidades utiliza o método, parcialmente, em seus sistemas de custeio.

Citam, ainda, o MCE como um modelo que utiliza, parcialmente, o método $A B C$, visto que o sistema proposto se apoia em sistemas tradicionais que utilizam esse método como filosofia de análise. A taxa reduzida de universidades europeias que implementam o método ABC demonstra, ainda, segundo os autores, a importância de discussão sobre a análise de custos e os benefícios da utilização deste método relativamente mais complexo. A seguir, apresentam-se os aspectos teóricos essenciais ao tema. Serão abordados assuntos relativos às Normas Brasileiras de Contabilidade aplicadas ao setor público e informações sobre a importância de padronização dos sistemas de custos em autarquias brasileiras bem como será apresentado um aparato dos principais métodos de custeio vigentes, com ênfase no 
$A B C$, visto que é o método utilizado no $M C E$, cuja apresentação antecede a proposta intervencionista aplicada na instituição estudada.

\section{REVISÃO DE LITERATURA}

No Brasil, a obrigatoriedade do Sistema de Informações de Custos do Setor Público (SICSP) em autarquias nacionais, estaduais e municipais, o cumprimento de legislações e normas de contabilidade nacionais, e, também, a adequação às normas internacionais, fazem com que a implantação de um sistema de custos em instituições públicas, que atenda a todas as diretrizes estabelecidas, torne-se um desafio a ser buscado. Sobre isso, Díaz et al (2013, p. 31) mencionam:

No caso brasileiro a principal pressão quanto à implantação de um modelo de contabilidade aplicada ao setor público como um todo, e não apenas às Universidades, refere-se à adequação do Brasil às práticas de contabilidade vigentes de acordo com os padrões estabelecidos nas Normas Internacionais de Contabilidade Aplicadas ao Setor Público. Este novo modelo a ser implantado tem como objetivo complementar resgatar o caráter científico da contabilidade, enfatizando a entidade pública como objeto de estudo em potencial dessa ciência.

As adequações das normas nacionais às internacionais vêm sendo aplicadas em muitos países e a sua implementação é um desafio em grande parte deles. Christiaen et al (2013), em um estudo que realiza um comparativo internacional sobre os efeitos das IPSAS na reforma dos relatórios financeiros governamentais europeus, destacam que, apesar da implementação internacional do regime de competência (contabilidade de exercício), os sistemas de informações financeiras do setor público europeu permanecem relativamente divergentes. Nos países europeus, a adequação de normas nacionais de 25 países - a maioria pertencente e alguns não pertencentes à União Europeia (UE) - em consonância às IFRS, têm sido estudadas de modo a classificar os sistemas contábeis para examinar as atuais diferentes abordagens nacionais europeias em relação às IFRS.

Christiaen at al (2013) afirmam, também, que as IFRS são largamente permitidas para empresas não financeiras europeias, contudo, a permissão não significa exatamente o uso real, conforme ficou demonstrado em sua pesquisa que apresenta dados sobre 
a quantidade de empresas europeias que adotam o IFRS. Em Chipre, por exemplo, cerca de $93 \%$ seguem as diretrizes do IFRS, muito impulsionado pelo requisito obrigatório neste país, já na Grécia, 20,9\% das empresas gregas estão usando o IFRS, enquanto que apenas $1 \%$ ou $2 \%$ das empresas na Alemanha e na Áustria adotam o IFRS. Já na Espanha e Portugal, cerca de 29 mil empresas adotam o IFRS, de acordo com o estudo de André (2017). Sobre a implementação do IFRS nas empresas portuguesas, Isidro e Pais (2017, p. 172) mencionam:

Em geral, todas as partes interessadas relevantes apoiam a adoção e implementação das IFRS em Portugal; acredita-se que a convergência para as IFRS é um meio importante para promover a tão desejada internacionalização da economia portuguesa e o acesso aos mercados financeiros globais; este ponto de vista é expresso, por exemplo, na introdução do Decreto-Lei n. 98/2015; o legislador afirma que a adoção em Portugal de regras de contabilidade alinhadas às normas internacionais representa uma clara redução nos custos de informação para pequenas e médias empresas, que promove a internacionalização de negócios e contribui para o crescimento sustentável proposto pela estratégia Europa 2020 (Tradução nossa).

Diante desta visão geral sobre as adequações às normas contábeis internacionais por parte dos países europeus, podemos considerar essas modificações como um passo importante para implementação de sistemas de custos padronizados em IES públicas, conforme orienta o MCE. Considerando esse contexto, a seguir são apresentadas as normas e diretrizes voltadas à contabilidade brasileiras aplicadas no setor público.

\subsection{NORMAS BRASILEIRAS DE CONTABILIDADE APLICADAS AO SETOR PÚBLICO}

A Norma Brasileira de Contabilidade, NBC TSP, que trata da "Estrutura Conceitual para Elaboração e Divulgação de Informação Contábil de Propósito Geral pelas Entidades do Setor Público", em revogação ao NBCT 16.2 de 2008, estabelece os conceitos referentes ao patrimônio público e seus sistemas contábeis e profere, ainda, que o principal objetivo de grande parte das entidades públicas é a prestação de serviços à sociedade e não a obtenção de lucros e retorno financeiro (Conselho Federal de Contabilidade [CFC], 2016). A Estrutura Conceitual definida pela NBC TSP 
passou a vigorar a partir de $1^{\circ}$ de janeiro de 2017 e engloba os seguintes conceitos (CFC, 2016):

1. Função, Autoridade e Alcance da Estrutura Conceitual;

2. Objetivos e Usuários da Informação Contábil de Propósito Geral das Entidades do Setor Público;

3. Características Qualitativas;

4. Entidade que Reporta a Informação Contábil;

5. Elementos das Demonstrações Contábeis;

6. Reconhecimento nas Demonstrações Contábeis;

7. Mensuração de Ativos e Passivos nas Demonstrações Contábeis;

8. Apresentação de Informação no Relatório Contábil de Propósito Geral das Entidades do Setor Público.

Com base na NBC TSP, a Tabela 1 apresenta os principais aspectos a serem avaliados em entidades do setor público.

Tabela 1: Aspectos considerados em empresas públicas

NBC TSP Aspectos a serem avaliados em entidades do setor público

a) Se a entidade prestou seus serviços à sociedade de maneira eficiente e eficaz;

b) Quais são os recursos atualmente disponíveis para gastos futuros, e até que ponto há restrições ou condições para a utilização desses recursos;

c) A extensão na qual a carga tributária, que recai sobre os contribuintes em períodos futuros para pagar por serviços correntes, tem mudado;

d) Se a capacidade da entidade para prestar serviços melhorou ou piorou em comparação com exercícios anteriores. 
Fonte: Conselho Federal de Contabilidade. NBC TSP - Estrutura Conceitual. 2016. Disponível em: http://www1.cfc.org.br/sisweb/SRE/docs/NBCTSPEC.pdf. Acesso em: $14 \mathrm{dez} .2019$.

\subsection{SISTEMA DE INFORMAÇÕES DE CUSTOS NO SETOR PÚBLICO}

O sistema de informação de custos brasileiro, nas esferas Federal, Estadual e Municipal, tem características específicas que levam seus respectivos gestores a buscarem diferentes alternativas para a melhoria no sistema de custos, de forma a gerar informações mais precisas para que, assim, possam subsidiar instrumentos para a tomada de decisões gerenciais. O Governo Federal, com a finalidade de subsidiar melhores condições e celeridade aos processos de transparência quanto à informação de custos, buscou alterar a legislação contábil bem como buscou por uma maior convergência com padrões internacionais, tornando, então, obrigatório que todas as entidades públicas passem a programar e implementar um novo sistema de informação contábil. Este fato promete mudar a cultura organizacional dos gestores públicos que possuem visão puramente orçamentária e não patrimonial quando o assunto é a tomada de decisão (Gama; Duque; Almeida, 2014).

A introdução da Lei de №. 4.320/1961, em seu Art. 85 e com a posterior aprovação do pronunciamento contábil do CFC n. 1.366 de 25 de novembro de 2011 e NBC T 16.11 (Resolução CFC, 2011), trouxe uma nova visão para a contabilidade pública brasileira, tendo em vista que estas vieram apoiar as funções da contabilidade, dentre elas o planejamento e o orçamento bem como visam evidenciar os custos dos serviços, atividades e projetos. Já a Lei Complementar n. 101 de 2000 determinou no Art. 50, inciso 3ㅜ, que "a Administração Pública manterá sistema de custos que permita a avaliação e o acompanhamento da gestão orçamentária, financeira e patrimonial" (Lei №. 101/2000, §1).

No entanto, não definiu e nem normatizou as diretrizes inerentes a como desenvolver o modelo da gestão de custos no setor público, o que, para Alonso (1999) e Mauss e Souza (2008) pode ocasionar em algumas dificuldades para a implantação do sistema de custos, como, por exemplo, pode acarretar na falta de normatização de modelo 
para os órgãos públicos, na falta de cultura da utilização do sistema, e, por fim, na ausência de conhecimentos sobre os conceitos e normas nacionais e internacionais de custos por parte dos colaboradores envolvidos e na complexidade da implantação de um novo ambiente organizacional.

\subsection{IMPORTÂNCIA DA PADRONIZAÇÃO DE MÉTODOS DE MENSURAÇÃO DE CUSTOS NAS IES BRASILEIRAS}

Soares e Cericato (2005) apontam, em suas reflexões, que há certa complexidade em identificar e comparar o custo-aluno entre as IES em razão da aplicação de metodologias de custeio diferentes. Os mesmos autores afirmam existir, hoje, quatro métodos de sistema de mensuração de custos e que sua padronização, ou seja, a adoção de uma única metodologia para todas as IES, seria um facilitador para este fim. Em consonância, Feijó (2013) defende haver outros fatores a serem replicados além da padronização de metodologia de custos, tais como:

a) Observância da competência à luz do reconhecimento das variações patrimoniais;

b) Maior controle quanto à gestão de custos, aplicada aos órgãos públicos, resultando em transparência, eficiência e eficácia frente aos processos de reconhecimento e aplicabilidade de modelos de mensuração de custos padronizados.

Costa et al (2009), por sua vez, ao argumentarem sobre as análises do sistema de custos da Universidade de Brasília, constataram ser de fundamental importância que estudantes, pesquisadores, mestres, doutores e gestores das IES do setor público discutam, analisem e estudem, exaustivamente, a questão da identificação dos modelos de mensuração de custos.

\subsection{CUSTEIO BASEADO EM ATIVIDADE (ABC)}

Os métodos de custeio existentes e comumente utilizados como base para os sistemas de custos, na prática dos gestores, são: a) custeio por absorção; b) custeio direto ou variável; c) custeio baseado em atividade (ABC) e d) custeio baseado em 
atividade e tempo, TDABC (Martins; Rocha, 2015). O Modelo de Custeio Espanhol, contudo, utiliza o método $A B C$, sendo este, portanto, o único método pormenorizado no presente estudo. O Custeio Baseado em Atividades, conhecido como ABC, é uma metodologia desenvolvida por Kaplan e Cooper (2000) com a função de facilitar a análise estratégica dos custos relacionados às atividades que impactam o consumo de recursos de uma organização. Embora sua origem tenha sido nas fábricas, é um poderoso método que pode ser aplicado em diferentes tipos de organizações.

De acordo com Nakagawa (2001), enquanto métodos tradicionais de custeio, como custeio por absorção ou custeio direto, baseiam-se, apenas, na precisão e exatidão dos números. Assim, o método $A B C$ busca, nesses números, as atribuições que asseguram a acurácia necessária à gestão de custos baseada em atividades. $O$ principal fator empregado no método $A B C$ refere-se à correta definição dos direcionadores de custos que, segundo Martins (2010), são: a) direcionadores de recursos e b) direcionadores de atividades. Segundo o autor, o direcionador de recursos identifica a maneira como as atividades consomem recursos e serve para custear as atividades, ou seja, demonstra a relação entre os recursos gastos e as atividades e o direcionador de atividades identifica a maneira como os produtos consomem atividades e serve para custear produtos (ou outros custeamentos), ou seja, indica a relação entre as atividades e os produtos.

\subsection{MODELO DE CUSTEIO ESPANHOL (MCE)}

O MCE (Modelo de Custeio Espanhol) foi desenvolvido especificamente para universidades pela OCU (Oficina de Cooperación Universitária) em parceria com a UMA (Universidade de Málaga) e publicado, pela primeira vez, em 2011, na obra de Díaz et al intitulada de "Libro Blanco de los Costes en las Universidades", com versão em língua portuguesa lançada no ano de 2013. O modelo utiliza como base o método de custeio $A B C$ e propõe conectar e integrar todas as universidades que implantam o sistema que, por sua vez, é uma aplicação multilíngue, cujo funcionamento se dá inteiramente on-line (DÍAZ et al, 2013). Este tópico é dedicado a apresentar, sucintamente, com base na obra de Díaz et al (2013), os aspectos e características do MCE bem como as suas fases de implantação. 


\subsubsection{FASES DE IMPLANTAÇÃO DO MODELO}

Para Díaz et al (2013) os elementos que compõem o sistema de informação requerido para a implantação podem ser divididos em oito fases, sendo que as quatro primeiras se caracterizam pela fase de preparação e obtenção dos dados e as quatro últimas representam o recebimento e processamento de dados já no sistema de custos em si . Os autores lembram, ainda, ser necessário que a IES tenha ciência do conjunto de atividades que compõem cada uma dessas fases e que embora não se trate de um guia de implantação, traz informações importantes quanto aos recursos que devem ser colocados à disposição do projeto de implantação do sistema. A Figura 1 apresenta essas fases.

Figura 1: Fases para a implantação do sistema de custos

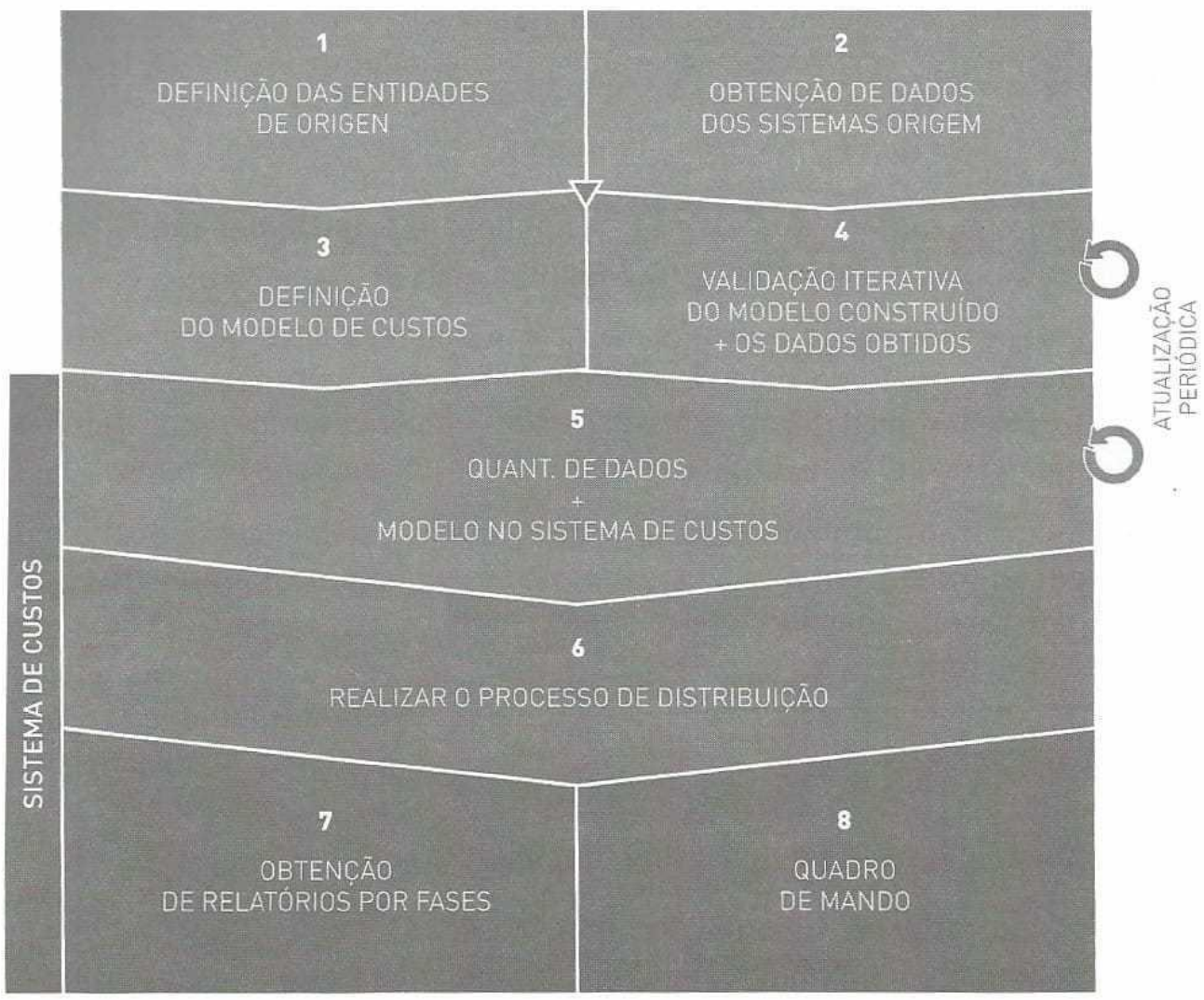

Fonte: Díaz et al (2013, p. 412). 
Já a Figura 2 exibe, de forma pormenorizada, o diagrama para definição do modelo de custos que corresponde à fase 3 de implantação. Segundo Díaz et al (2013), após finalizada todas as fases de planejamento, preparação e implantação do modelo, trabalho este realizado, conjuntamente, entre a IES e a equipe de implantação do MCE, o sistema de custeio está pronto para ser implementado na IES.

Figura 2: Digrama para definição do modelo de custos

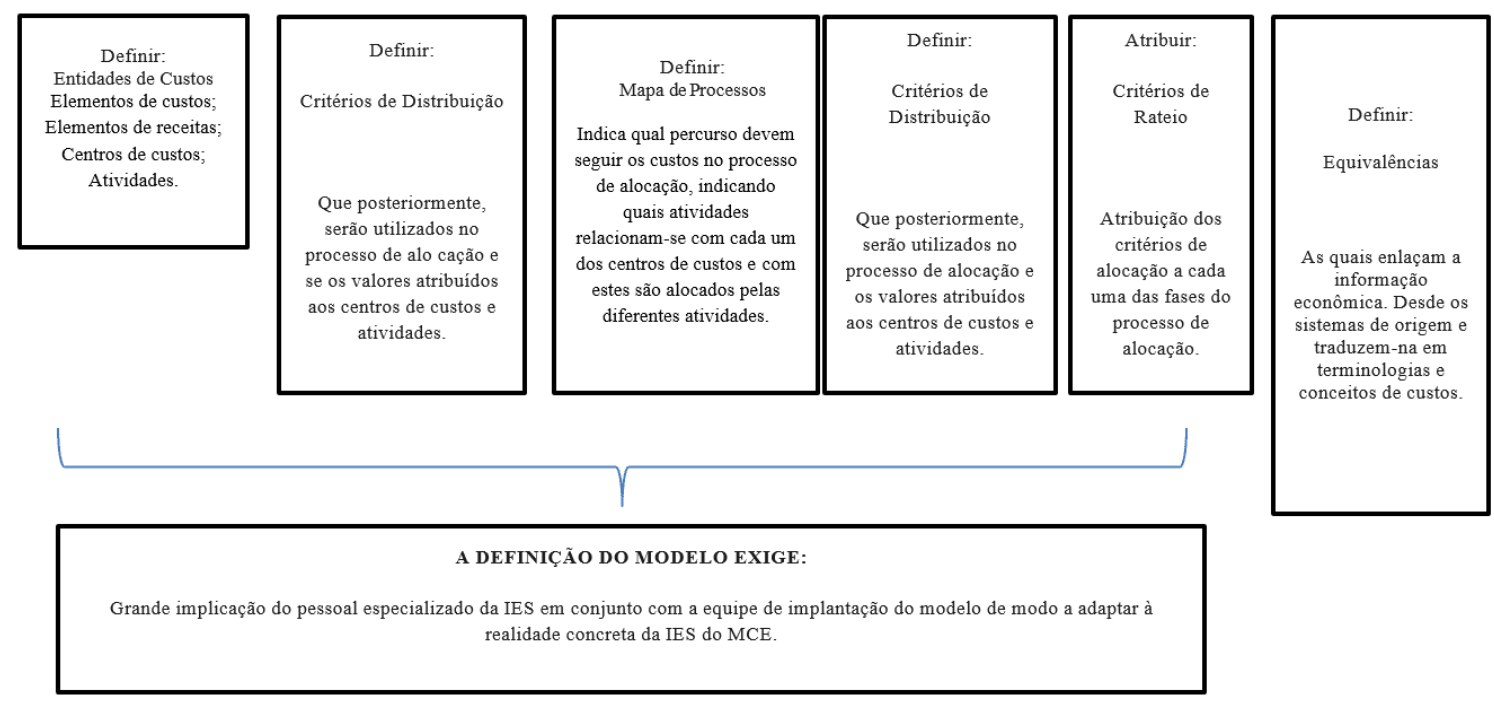

Fonte: Díaz et al (2013, pp. 414-415).

\section{PROCEDIMENTOS METODOLÓGICOS}

Esta pesquisa caracteriza-se como exploratória, descritiva e intervencionista. $\mathrm{Na}$ primeira etapa, apresenta-se a revisão da literatura, fundamentos teóricos e métodos existentes concernentes ao estudo bem como a coleta de dados e extração de arquivos da instituição amostra, pertinentes ao desenvolvimento da pesquisa. Quanto aos procedimentos, optou-se pelo uso da técnica intervencionista, por meio da abordagem de pesquisa-ação, baseada em estudo de caso com viés construtivista, utilizando-se de observação, investigação e intervenção. Tal método mostrou-se pertinente ao presente projeto, dada sua característica de junção entre teoria e prática, proporcionando, assim, resultados relevantes. Segundo Oyadomari et al (2014), a abordagem intervencionista da pesquisa-ação caracteriza-se pela postura 
diferenciada do pesquisador, pois atua, também, como um agente interventor no processo a ser analisado.

Os autores apontam para o aspecto colaborativo entre pesquisador e práticos, visto que estes possuem similar interesse àquele no que se refere à busca por um entendimento dos modelos organizacionais estudados que possam vir a explicitar, com propriedade, os resultados da experiência. Optou-se por seguir a tipologia construtivista dada sua pretensão de desenvolver solução para um problema prático (Labro; Tuomela, 2003) a partir do método de pesquisa intervencionista, em que se procura unir a teoria e ação ou prática, isto é, desenvolver o conhecimento e a compreensão como parte da prática, no intuito de solucionar o problema.

A natureza da pesquisa fez com que se escolhesse uma Instituição de Ensino Superior Pública, autarquia municipal, que aceitou a proposta, mas cuja identificação optou-se por não divulgar, atendendo à solicitação da própria IES. Participaram da amostra os profissionais de nível estratégico, responsáveis pela tomada de decisão e os gestores de todas as seções envolvidos com o desenvolvimento e possível implantação de um projeto que proporcionará uma nova ferramenta para a tomada de decisões. Os dados coletados na IES foram, inicialmente, analisados qualitativamente, de forma a compreender as necessidades da IES e seus departamentos para posterior tratamento dessa informação, categorizando-a e organizando-a de maneira a propiciar a projeção de um modelo de sistema de custos padronizado.

\section{DESENVOLVIMENTO DA PROPOSTA INTERVENCIONISTA}

Primeiramente, buscou-se a classificação das áreas, subdivisões e/ou coordenadorias da IES amostra que deveriam ser analisadas no presente estudo e que têm relação com as categorias das fontes geradoras de custos, demonstradas no modelo elaborado, conforme mostra a Tabela 2. 
Tabela 2: Categorias das fontes geradoras de custos utilizadas na pesquisa

\begin{tabular}{|c|c|c|c|}
\hline $\begin{array}{l}\text { Custos } \\
\text { de ensino }\end{array}$ & $\begin{array}{l}\text { Custos de P\&D } \\
\text { e extensão }\end{array}$ & $\begin{array}{l}\text { Custos } \\
\text { administrativos }\end{array}$ & $\begin{array}{l}\text { Custos de } \\
\text { manutenção }\end{array}$ \\
\hline $\begin{array}{l}\text { Salário dos } \\
\text { professores }\end{array}$ & $\begin{array}{l}\text { Salário dos } \\
\text { profissionais } \\
\text { envolvidos }\end{array}$ & Diretoria & $\begin{array}{l}\text { Manutenção de } \\
\text { equipamentos }\end{array}$ \\
\hline $\begin{array}{l}\text { Equipamentos e } \\
\text { materiais em sala } \\
\text { de aula }\end{array}$ & $\begin{array}{l}\text { Material para a } \\
\text { realização das } \\
\text { atividades }\end{array}$ & $\begin{array}{l}\text { Coordenação } \\
\text { dos campi }\end{array}$ & $\begin{array}{l}\text { Manutenção da } \\
\text { biblioteca }\end{array}$ \\
\hline Bolsas de estudos & $\begin{array}{l}\text { Bolsas de P\&D e } \\
\text { extensão }\end{array}$ & $\begin{array}{l}\text { Coordenadores } \\
\text { das unidades }\end{array}$ & $\begin{array}{l}\text { Manutenção } \\
\text { laboratórios }\end{array}$ \\
\hline
\end{tabular}

Fonte: Autor (2019)

As áreas determinadas para análise na IES amostra foram as Unidades Administrativas e Secretaria Geral que correspondem às categorias Custos Administrativos e Custos de Manutenção e as Coordenadorias tanto de graduação como de pós-graduação e pesquisa e desenvolvimento que, por sua vez, correspondem às categorias Custos de Ensino e Custos de Pesquisa e Desenvolvimento (P\&D) e Extensão, conforme mostra a Figura 2. Inicialmente, coletaram-se os dados de cada sistema de informação da IES, identificando e definindo as entidades de origem antes de sugerir e aplicar o MCE. Obtiveram-se os dados dos sistemas consolidados das despesas e receitas para posterior identificação dos custos diretos e indiretos de cada sistema envolvido a fim de definir os devidos centros de custos.

Em seguida, direcionou-se cada custo, relacionando-os à sua respectiva atividade $\mathrm{e}$ fez-se a validação iterativa do modelo construído de acordo com o modelo de custeio $A B C$ bem como se realizou o processo de distribuição das despesas e receitas com base no MCE. Os dados e informações de custos obtidos da IES foram extraídos dos seus sistemas de informações, sendo, posteriormente, tratados e categorizados de 
forma a atender a padronização necessária para a elaboração do modelo de custeio proposto neste trabalho. Seguiram-se, nesta etapa, todas as fases requeridas para implantação do MCE (ver Figura 1) e observou-se a ausência de um processo de gestão de custos, havendo, contudo, nove sistemas de informações independentes e não integrados por meio do qual a IES administra seus dados financeiros. Elaborouse, então, o desenho do modelo de sistema de custos proposto, com base na implantação de um protótipo do MCE, apresentado em organograma na Figura 3.

Figura 3: Organograma do Sistema de Custeio Projetado para a IES amostra

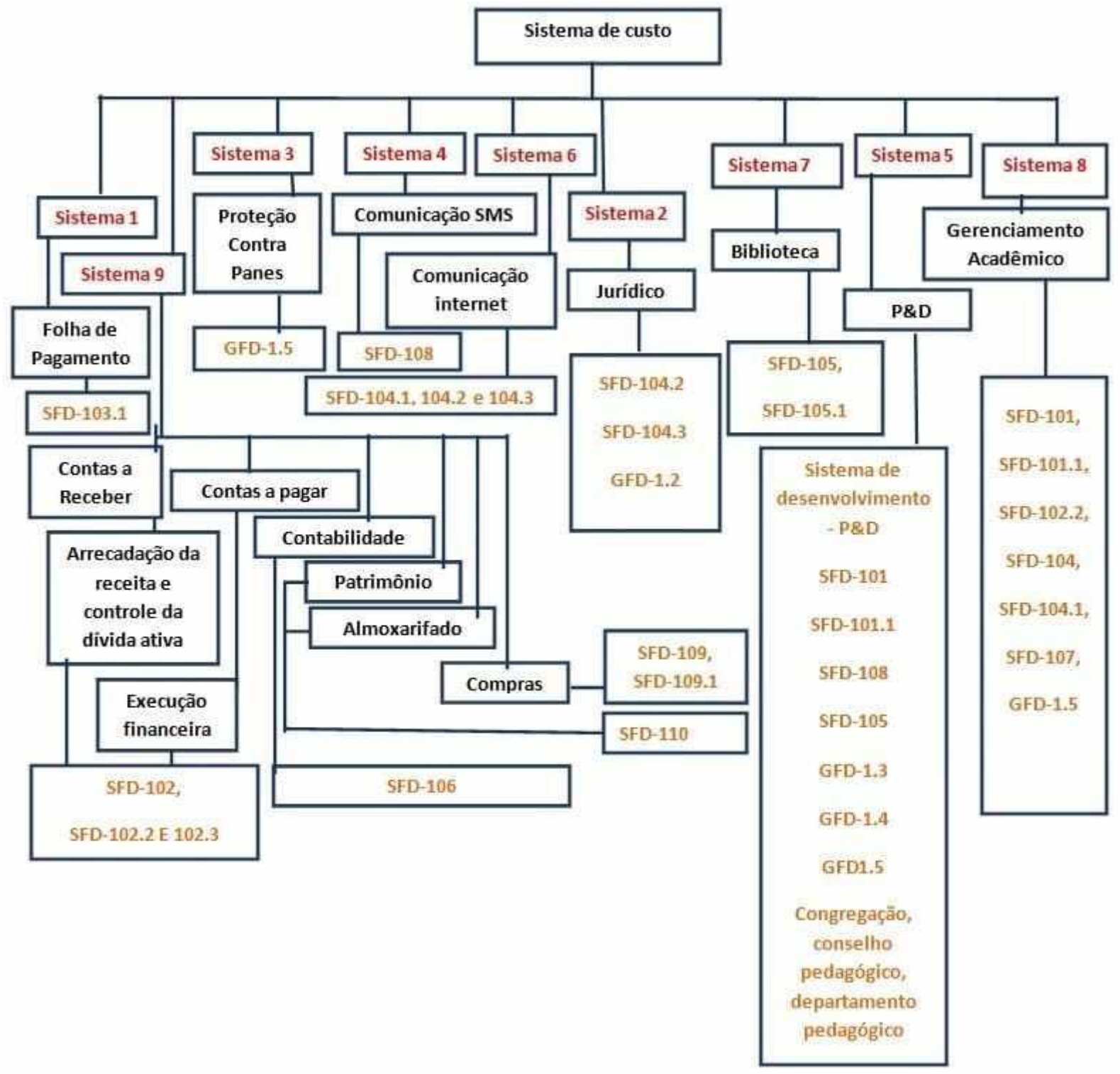

Fonte: Autor (2019) 


\section{ANÁLISE E INTERPRETAÇÃO DOS RESULTADOS}

Os resultados obtidos entre despesas e receitas, ao analisar a distribuição dos custos e considerando todas as receitas da IES amostra, o que inclui os repasses municipais e ativos financeiros, indicaram um alto percentual de participação da Folha de Pagamento nos custos totais, chegando a 64\%, sendo que a Lei de Responsabilidade Fiscal, em seu artigo 19, estabelece o percentual máximo de 60\% para autarquias municipais (Lei n. 101, 2000), evidenciando, portanto, que os resultados encontrados referentes à Folha de Pagamento apontam um nível crítico. A Tabela 3 exibe o Resultado por Despesa referente ao ano-calendário de 2017.

Tabela 3: Resultado por despesas na IES amostra (\%)

\begin{tabular}{|l|r|}
\hline Despesas 2017 & $\%$ \\
\hline Folha de pagamento & 64 \\
\hline $\begin{array}{l}\text { Tecnologia e Informação } \\
\text { (TI) }\end{array}$ & 11 \\
\hline Serviços de Terceiros & 11 \\
\hline Administração & 9 \\
\hline Consumos diversos & 3 \\
\hline Manutenção diretos & 1 \\
\hline Impostos & 1 \\
\hline (IMPDIR) & $\mathbf{1 0 0}$ \\
\hline Total & \\
\hline
\end{tabular}

Fonte: Autor (2019).

Três cenários foram analisados para a apuração de resultados. O primeiro considerou todos os aportes financeiros que a IES amostra possui e o segundo e o terceiro foram analisados sem tais aportes, já que os mesmos possuem vigência predeterminada. $\mathrm{Na}$ Figura 4 observa-se que as receitas e despesas totais por aluno/ano estão alinhadas e em harmonia ao considerar os aportes financeiros na receita total. 
Figura 4: Resultado entre despesa e receita considerando a totalidade das receitas $(\%)$

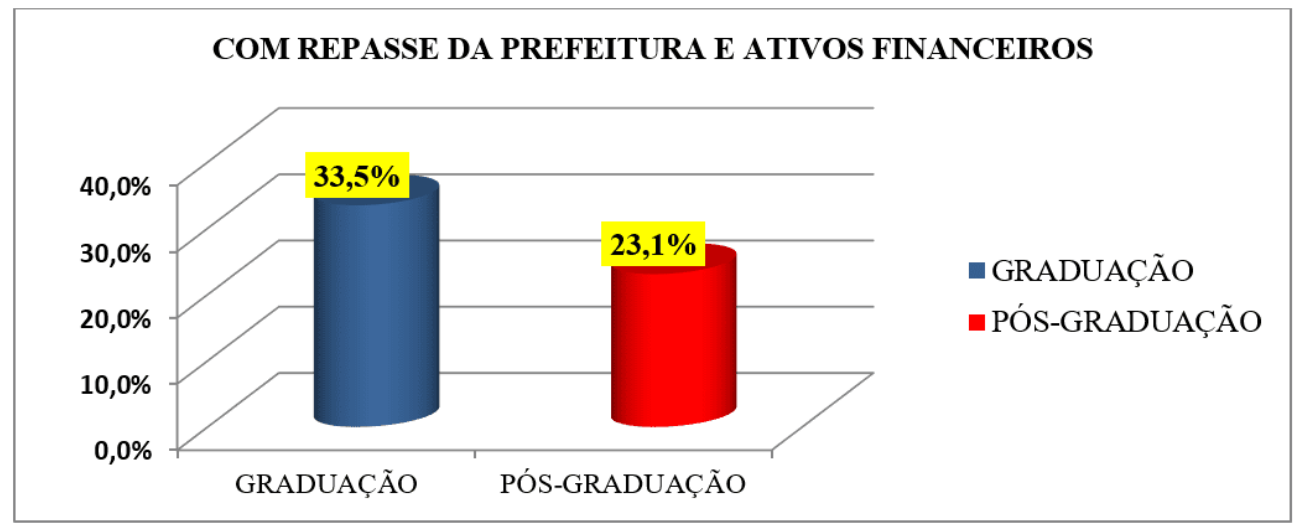

Fonte: Autor (2019).

Contudo, ao avaliar um novo cenário, sem considerar o repasse municipal nas receitas (cenário este que se optou por analisar dada a existência de um acordo entre a IES amostra e a prefeitura, fruto de uma dívida e que possui prazo para finalizar nos próximos dez anos), possibilitou uma análise acerca das despesas e receitas da IES de maneira mais realista. Neste segundo cenário, mostrado na Figura 5, ao analisar a relação entre despesas e receitas, retirando das receitas totais o repasse da prefeitura, obteve-se, como resultado, um cenário positivo na graduação de 10,3\% e um déficit de $0,1 \%$ na pós-graduação.

Figura 5: Resultado entre despesa e receita sem repasse municipal na receita (\%)

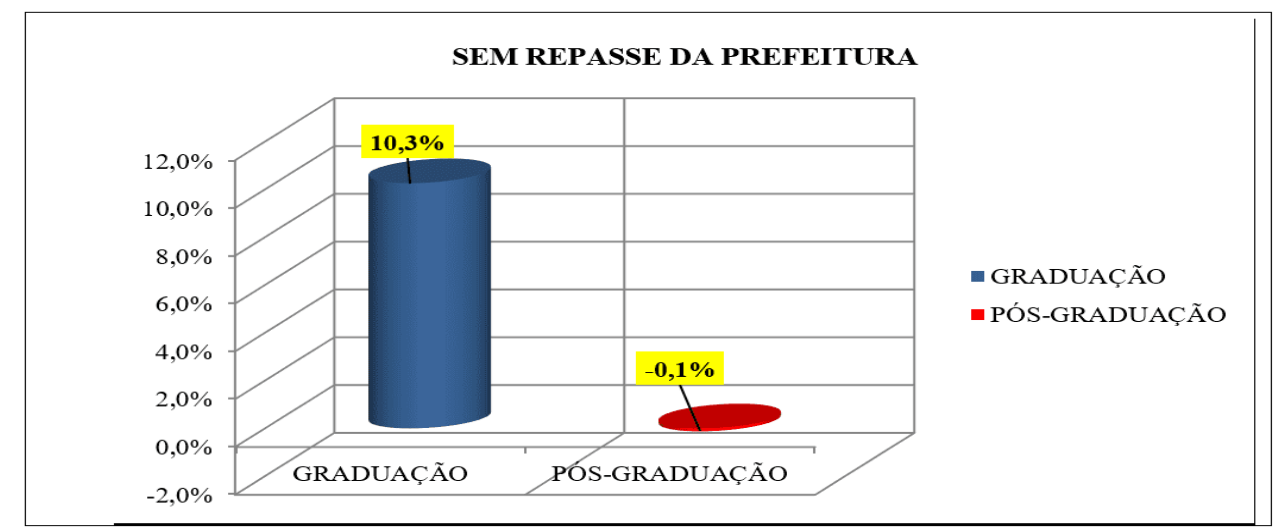

Fonte: Autor (2019) 
Já no terceiro e último cenário, o mais desfavorável, e, portanto, o que desconsiderou tanto os repasses da prefeitura quanto os proventos advindos de ativos financeiros, obteve um resultado bastante preocupante, com déficits de 9,4\% na graduação e 19,8 na pós-graduação, conforme mostra a Figura 6.

Figura 6: Resultado entre despesa e receita sem repasse municipal e ativos na receita (\%)

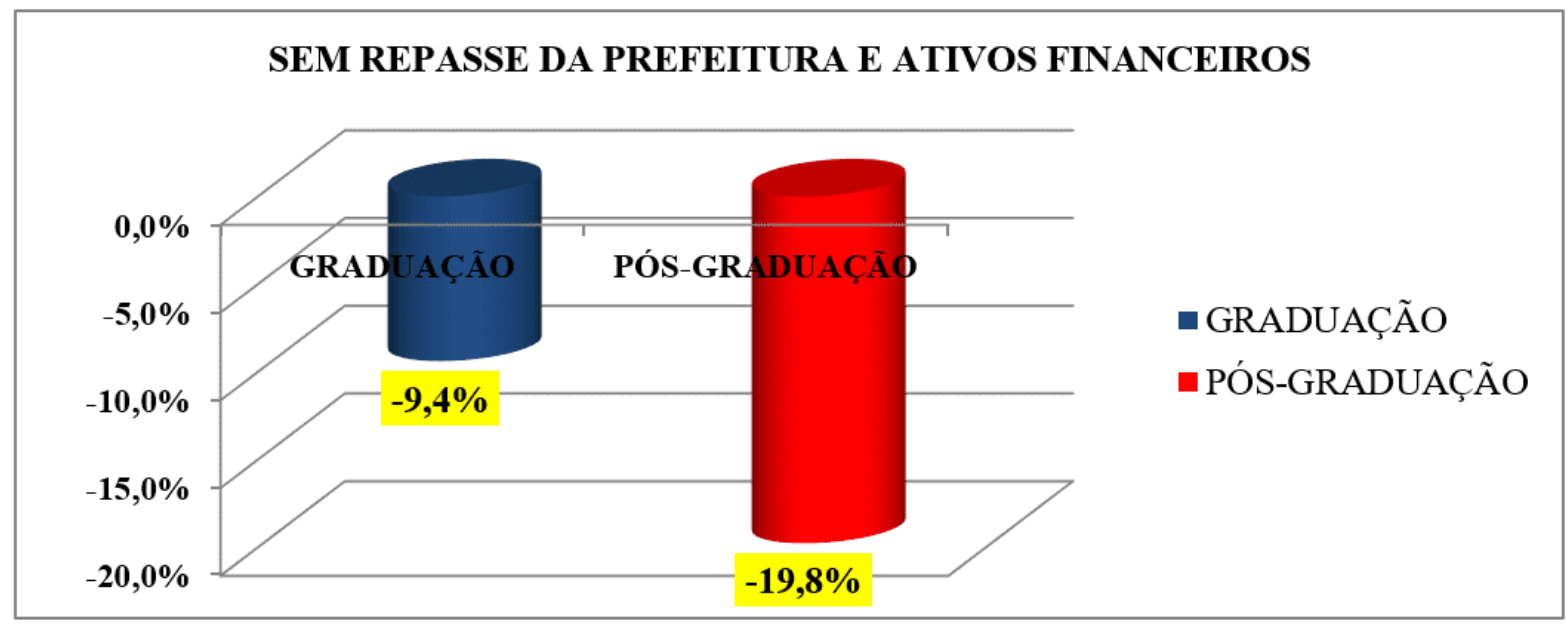

Fonte: Autor (2019)

Ao realizar o processo de distribuição dos custos, a partir dos demonstrativos contábeis do ano-calendário de 2017, para cálculo do custo-aluno da IES amostra, a Tabela 4 exibe os valores consolidados, anual e mensal, das receitas e despesas e a apuração do custo-aluno de graduação e pós-graduação.

Tabela 4: Apuração do custo-aluno da IES amostra (em milhares de reais)

Consolidado anual e mensal das despesas e receitas e a apuração do custo-aluno

\begin{tabular}{|l|l|l|l|}
\hline & & Graduação & \multicolumn{2}{|l|}{ Pós-Graduação } \\
\hline Despesa & $\mathrm{R} \$$ /Aluno - Ano & $11.334,37$ & $3.834,75$ \\
\hline Despesa & $\mathrm{R} \$$ /Mensalidade & 944,00 & \multicolumn{2}{|c}{319,00} \\
\hline Receita total & $\mathbf{R}$ /Aluno - Ano & $\mathbf{1 5 . 1 2 7 , 0 0}$ & $\mathbf{4 . 7 1 9 , 0 0}$ \\
\hline Receita total & $\mathbf{R}$ /Mensalidade & $\mathbf{1 . 2 6 0 , 0 0}$ & $\mathbf{3 9 3 , 0 0}$ \\
\hline
\end{tabular}


Fonte: Autor (2019)

Apurou-se, portanto, a partir dos resultados totais das despesas e receitas, o custoaluno anual de $\mathrm{R} \$ 11.334,37$ (onze mil, trezentos e trinta e quatro reais e trinta e sete centavos) por aluno de graduação e $\mathrm{R} \$ 3.834,75$ (três mil e oitocentos e trinta e quatro reais e setenta e cinco centavos) por aluno de pós-graduação. Considerando o melhor cenário de receita apresentado neste trabalho, foi possível apurar que o custo-aluno representa à IES amostra, em média, $28 \%$ das despesas totais, sendo $33,5 \%$ para os alunos de graduação e 23,1\% para os alunos de pós-graduação.

\section{CONSIDERAÇÕES FINAIS}

A análise estratégica a partir da análise de custos mostra clara importância para qualquer organização ou entidade, pois, sem ela, a manutenção da vantagem competitiva por meio do uso adequado dos recursos torna-se uma tarefa difícil de ser alcançada. Tratando-se de IES públicas, cujo foco está na satisfatória prestação de serviços e não na obtenção do lucro, a gestão de custos é igualmente importante para o controle dos recursos públicos e para melhorias nos serviços e prestação de contas à sociedade. $O$ presente estudo buscou identificar e demonstrar as especificidades do custeio do serviço prestado em uma IES pública brasileira, de modo a possibilitar não somente a apuração do custo-aluno praticado na referida, mas, principalmente, subsidiar práticas de controle gerencial, propiciando a otimização dos processos de tomadas de decisões que se relacionam diretamente com o desempenho financeiro de IES públicas para propor a adoção do MCE aqui apresentada.

Acredita-se que este projeto tenha alcançado o objetivo de apurar o custo por aluno em uma IES pública brasileira de modo a otimizar os processos de tomada de decisão gerencial que se relacionam diretamente com o desempenho financeiro da instituição, possibilitando a alocação dos recursos aos objetos de custo de forma mais eficiente, permitindo a mensuração acurada dos custos e contribuindo efetiva e economicamente para uma melhor análise dos processos de trabalho ao eliminar desperdícios e otimizar o uso dos recursos públicos orçamentários. Os resultados alcançados, contudo, apontam que os dados da IES amostra no decorrer da proposta 
intervencionista demonstraram níveis críticos no que tange às despesas com pessoal frente às receitas, visto que a LRF estabelece o percentual máximo de $60 \%$ da despesa total com pessoal em relação à receita corrente líquida e o resultado encontrado na IES amostra aponta o percentual de $64 \%$.

Verificou-se, também, resultados favoráveis no que tange à graduação e pósgraduação, quando analisado o cenário que considera todos os aportes financeiros atuais da IES amostra, apresentando, 33,5\% e 23,1\% de resultado positivo. Já no cenário mais desfavorável, cenário em que se desconsideram na receita os repasses e ativos financeiros, a graduação chega a 9,4\% de déficit e a pós-graduação a 19,8\% de déficit nas mensalidades por aluno. Ao final, foi possível analisar, empiricamente, a aplicabilidade do sistema de custos em uma IES pública brasileira, as dificuldades e desafios enfrentados para tal bem como a análise dos custos da IES amostra e a apuração real custo-aluno apontaram o custo-aluno anual de $\mathrm{R} \$ 11.334,37$ (onze mil, trezentos e trinta e quatro reais e trinta e sete centavos) por aluno de graduação e $R \$$ $3.834,75$ (três mil, oitocentos e trinta e quatro reais e setenta e cinco centavos) por aluno de pós-graduação.

Esse estudo demonstrou a dependência da IES nos recursos públicos para cumprir a Lei da Responsabilidade Fiscal e também para permitir o equilíbrio de suas contas. É, portanto, uma realidade a ser analisada. Nesse contexto, a pesquisa revelou, a partir dos resultados aqui analisados, que o planejamento de gastos e os investimentos devem estar compatíveis com os anseios da população assim como deve estar, também, em consonância com o planejamento e desenvolvimento da educação no país. Devido a tais fatores deve considerar, portanto, a estrutura deficitária no aporte para sua manutenção, como, por exemplo, a discussão sobre políticas públicas.

\section{REFERÊNCIAS}

ALONSO, M. Custos no serviço público. Revista do Serviço Público, v. 50, n. 1, p. 37-63, jan.- mar. 1999. 
ANDRÉ, P. The Role and Current Status of IFRS in the Completion of National Accounting Rules - Evidence from European Countries. Accounting in Europe, v. 14, n. 2, p. 1-12, 2017.

CHAN, J. L. International Public Sector Accounting Standards: Conceptual and Institutional Issues. In: The Harmonization of Government Accounting and the Role of IPSAS. Milan, Italy: McGraw-Hill, 2009.

Conselho Federal de Contabilidade. NBC TSP - Estrutura Conceitual. 2016. Disponível em: http://www1.cfc.org.br/sisweb/SRE/docs/NBCTSPEC.pdf. Acesso em: 16 dez. 2019.

Constituição da República Federativa do Brasil de 1988. Artigo 74 - Os Poderes Legislativo, Executivo e Judiciário manterão, de forma integrada, sistema de controle interno com a finalidade de... Senado. Brasília, DF.

COSTA, A. J. B. et al. Custo aluno do sistema universidade aberta do Brasil: 0 caso da universidade de Brasília. 2009. Disponível em: http://www.uab.unb.br/index.php/canais/publicacoes/cat_view/90publicacoes?limit=10\&limitstart=0\&order=hits\&dir=DESC. Acesso em: 16 dez. 2019.

Christiaen, J. et al. The Effect of IPSAS on Reforming Governmental Financial Reporting: An International Comparison. In: Working Paper of Faculty of Economics and Business Administration, 2013.

DÍAZ, D. C. et al. Livro Branco dos Custos em Universidades. Madri: Oficina de Cooperación Universitária, 2013.

FARIA, C. A implantação do sistema gerencial de custos (SISCUSTOS) desenvolvido pelo exército brasileiro: Estudo de caso na $1^{\underline{a}}$ inspetoria de contabilidade e finanças do exército. 2010. 140 f. Dissertação (Mestrado em Ciências Contábeis) - Universidade do Estado do Rio de Janeiro, Rio de Janeiro, 2010. 
FElJÓ, P. H. Entendendo as mudanças na contabilidade aplicada ao setor público. Brasília: Gestão Pública, 2013.

GAMA, J. R. et al. Convergência brasileira aos padrões internacionais de contabilidade pública vis-à-vis estratégias top-dow e bottom-up. Revista de Administração Pública (RAP), v. 48, n. 1, p. 183-206, 2014.

Isidro, H; PAIS, C. The Role and Current Status of IFRS in the Completion of National Accounting Rules - Evidence from Portugal. Accounting in Europe, v. 14, n. 1-2, p. 164-176, 2017.

Kaplan, R; Cooper, R. Custo e Desempenho: Administrando seus custos para ser mais competitivo. $2^{\mathrm{a}}$ ed. São Paulo: Futura, 2000.

Labro, E; Tuomela, T. On bringing more action into management accounting research: Process considerations based on two constructive case studies. European Accounting Review, v. 12, n. 3, p. 409-442, 2003.

Lei n. 4.320, de 17 de março de 1964. Dispõe sobre normas gerais de direito financeiro para elaboração e controle dos orçamentos e balanços da União, dos Estados, dos Municípios e do Distrito Federal. Diário Oficial da República Federativa do Brasil, Brasília, DF.

Lei Complementar n. 101, de 04 de maio de 2000. Lei de Responsabilidade Fiscal. Estabelece normas de finanças públicas voltadas para a responsabilidade na gestão fiscal e dá outras providências. Diário Oficial da República Federativa do Brasil, Brasília, DF.

MACHADO, N. Sistema de Informação de Custos: Diretrizes para Integração ao Orçamento Público e à Contabilidade Governamental. 2002. 221 f. Tese (Doutorado em Controladoria e Contabilidade) - Universidade de São Paulo, São Paulo, 2002. 
MACHADO, R. et al. Mudanças de critério contábil na depreciação no setor público: Um relato dos procedimentos realizados em uma instituição pública. Publ. UEPG Ci. Soc. Apl., v. 20, n. 1, p. 99-111, 2012.

MARION, J. C. Contabilidade Empresarial. 15ª ed. São Paulo: Atlas, 2015.

MARTINS, E. Contabilidade de Custos. 10ª ed. São Paulo: Atlas, 2010.

MARTINS, E; Peixinho, R. M. T. 2017. Desenvolvimento de um sistema de contabilidade de gestão: $O$ caso da Universidade do Algarve. Dos Algarves: A Multidisciplinary e-Journal. Disponível em: http://www.dosalgarves.com/rev/N29/5rev29.pdf. Acesso em: 16 dez. 2019.

MARTINS, E; ROCHA, W. Métodos de custeio comparados: Custos e margens analisados sob diferentes perspectivas. $2^{2}$ ed. São Paulo: Atlas, 2015.

Mauss, C. V; SOUZA, M. A. Gestão de custos aplicada ao setor público: Modelo para mensuração e análise da eficiência e eficácia governamental. São Paulo: Atlas, 2008.

Nakagawa, M. ABC - Custeio baseado em atividades. $2^{\mathrm{a}}$ ed. São Paulo: Atlas, 2001.

Oyadomari, J. C. T. et al. Pesquisa Intervencionista: Um ensaio sobre as oportunidades e riscos para pesquisa brasileira em contabilidade gerencial. Advances in Scientific and Applied Accounting, v. 7, n. 2, p. 244-265, 2014.

QUEIROZ, I. A. S; RODRIGUES, A. O efeito das Normas Internacionais de Contabilidade do Setor Público (IPSAS) sobre a aplicabilidade dos índices de Kohama para análise de Balanços Patrimoniais da União. Pensar Contábil, v. 14, n. 55, p. 2431, 2012.

Resolução CFC n. 1.366 de 25 de novembro de 2011. NBC T 16.11 - Sistema de Informação de Custos do Setor Público. Disponível em: http://www1.cfc.org.br/sisweb/SRE/docs/Res_1366.pdf. Acesso em: 16 dez. 2019. 
MELLO, G. S. Sistema de Custos na Administração Pública: Análise da implantação do método $A B C$ em prefeituras de pequeno porte. 2006. 123 f. Dissertação (Mestrado em Contabilidade) - Universidade Federal de Itajubá, Itajubá, 2006.

SOARES, T. C; Cericato, D. Custo por aluno: Algo fácil de comparação? In: Colóquio Internacional sobre Gestión Universitaria em América Del Sur, 2005.

Tribunal de Contas da União. Acórdão de Relação 1078/2004 - Segunda Câmara TCU de 04 de agosto de 2004. 2004. Disponível em: https://contas.tcu.gov.br/pesquisaJurisprudencia/\#/detalhamento/11/109020010.PRO C/\%2520/DTRELEVANCIA\%2520desc\%252C\%2520NUMACORDAOINT\%2520des c/false/1/false. Acesso em: 16 dez. 2019.

Enviado: Novembro, 2019.

Aprovado: Dezembro, 2019. 